\title{
PNPLA3 Gene Polymorphism Is Associated With Predisposition to and Severity of Alcoholic Liver Disease
}

\author{
Habeeb Salameh, MD¹, Evan Raff, MD², Angelika Erwin, MD³, Devanshi Seth, $\mathrm{PhD}^{4,5,6}$, Hans Dieter Nischalke, MD, \\ Edmondo Falleti, MD ${ }^{8}$, Maria Antonella Burza, PhD, MD9 , Julian Leathert, M.Phillo, Stefano Romeo, MD, PhD ${ }^{9,11}$, \\ Antonio Molinaro, MD ${ }^{9}$, Stefano Ginanni Corradini, MD, PhD ${ }^{12}$, Pierluigi Toniutto, MD ${ }^{13}$, Spengler Ulrich, MD $^{7}$, \\ Ann Daly, PhD ${ }^{14}$, Christopher P. Day, MD ${ }^{14}$, Yong-Fang Kuo, PhD ${ }^{15}$ and Ashwani K. Singal, MD, MS ${ }^{16}$
}

OBJECTIVES: The genetic polymorphism with an isoleucine-to-methionine substitution at position 148 (rs738409 $\mathrm{C}>\mathrm{G}$ ) in the patatin-like phospholipase domain protein 3 (PNPLA3) gene confers risk of steatosis. PNPLA3 polymorphism is shown to be associated with alcoholic liver disease (ALD). We performed a systematic review and meta-analysis to examine association of this genetic polymorphism with ALD spectrum and its severity.

METHODS: $\quad$ Medline, Embase, and Cochrane Library were searched for studies on association of PNPLA3 polymorphism and ALD spectrum: alcoholic fatty liver (AFL), alcoholic liver injury (ALI), alcoholic cirrhosis (AC), and hepatocellular carcinoma (HCC). Pooled data are reported as odds ratio (OR) with $95 \%$ confidence interval. Heterogeneity was assessed using the $R$ statistics and publication bias using Egger's test and Begg and Mazumdar's test. Individual participant data obtained from five studies were used for subgroup analyses.

RESULTS: $\quad$ Among 10 studies included in this pooled analysis, compared with controls, OR for rs738409 CG and GG among ALI patients was 1.45 (1.24-1.69) and 2.22 (1.50-3.28), respectively, compared with CC. Respective OR among AC patients was 2.09 (1.79-2.44) and 3.37 (2.49-4.58) and among AC patients with HCC was 2.87 (1.61-5.10) and 12.41 (6.99-22.03). Data for AFL were inconsistent. Among ALD patients, OR of CG and GG genotypes was 2.62 (1.73-3.97) and 8.45 (2.52-28.37), respectively, for AC compared with fatty liver (FL) patients. Similar OR for AC compared with ALI was 1.98 (1.24-3.17) and 3.86 (1.18-12.60). The OR for CG and GG genotypes among AC patients for HCC occurrence was 1.43 (0.76-2.72) and 2.81 (1.57-5.01), respectively. Individual participant data analysis showed age to predispose to AC among ALI patients.

CONCLUSIONS: PNPLA3 genetic polymorphism (rs738409 C>G) is associated with increased risk for the entire spectrum of ALD among drinkers including ALI, AC, and HCC. Studies are needed to clarify association of PNPLA3 polymorphism and steatosis in alcoholics. PNPLA3 gene may potentially be a therapeutic target in ALD.

SUPPLEMENTARY MATERIAL is linked to the online version of the paper at http://www.nature.com/ajg

Am J Gastroenterol 2015; 110:846-856; doi:10.1038/ajg.2015.137; published online 12 May 2015

\footnotetext{
${ }^{1}$ Department of Internal Medicine, University of Texas Medical Branch, Galveston, Texas, USA; ${ }^{2}$ Department of Internal Medicine, University of Alabama, Birmingham, Alabama, USA; ${ }^{3}$ Genomic Medicine Institute, Cleveland Clinic Foundation, Cleveland, Ohio, USA; ${ }^{4}$ Drug Health Services, Royal Prince Alfred Hospital, Camperdown, New South Wales, Australia; ${ }^{5}$ Centenary Institute of Cancer Medicine and Cell Biology, Camperdown, New South Wales, Australia; ${ }^{6}$ Faculty of Medicine, University of Sydney, Sydney, New South Wales, Australia; 7 Department of Internal Medicine, University of Bonn, Bonn, Germany; ${ }^{8}$ Laboratory Medicine_-Istituto Patologia Clinica, Azienda Ospedaliero Universitaria, Udine, Italy; ${ }^{9}$ Institute of Medicine, Department of Molecular and Clinical Medicine, Wallenberg Laboratory, University of Gothenburg, Gothenburg, Sweden; ${ }^{10}$ Institute of Cellular Medicine, Newcastle University Medical School, Newcastle upon Tyne, UK; ${ }^{11}$ Department of Medical and Surgical Science, University Magna Grecia of Catanzaro, Clinical Nutrition Unit, Germaneto, Catanzaro, Italy; ${ }^{12}$ Department of Clinical Medicine, Division of Gastroenterology, Sapienza University of Rome, Rome, Italy; ${ }^{13}$ Department of Medical Sciences Experimental

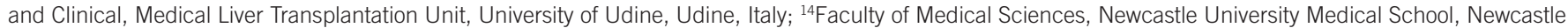
upon Tyne, UK; ${ }^{15}$ Department of Biostatistics, University of Texas Medical Branch, Galveston, Texas, USA; ${ }^{16}$ Division of Gastroenterology and Hepatology, University of Alabama, Birmingham, Alabama, USA. Correspondence: Ashwani K. Singal, MD, MS, Division of Gastroenterology and Hepatology, University of Alabama at Birmingham, 1808 7th Avenue South, BDB 351, Birmingham, Alabama 35233, USA. E-mail: ashwanisingal.com@gmail.com Received 7 November 2014; accepted 1 April 2015
} 


\section{INTRODUCTION}

Alcohol abuse is a common cause of cirrhosis and indication for liver transplantation. Clinical spectrum of alcohol-related liver disease includes simple steatosis or alcoholic fatty liver (AFL), alcoholic liver injury with elevated transaminases but without cirrhosis (ALI), alcoholic cirrhosis (AC), and hepatocellular carcinoma (HCC). Amount of alcohol consumption is the most important factor in the development of ALI and AC (1). However, only $\sim 10-20 \%$ of heavy drinkers develop AC, suggesting a role of other host factors and comorbidities predisposing to ALI and its progression to AC and HCC (2). Data on genetic predisposition to alcoholism and alcoholic liver disease (ALD) among monozygotic twins (3), and on ethnic variations on ALD-related mortality independent of amount of alcohol use, support the role of genetic factors in mediating ALD (4-6). Single-nucleotide polymorphisms within genes of cytokines, alcohol-metabolizing enzymes, and antioxidant enzymes have been shown to be associated with progression of alcohol-induced liver fibrosis (7). However, data on association of these genetic factors in the development of ALD have remained conflicting until a few years ago (8).

Recently, a genome-wide screen in a population of Hispanic, African, and European Americans from the Dallas Heart Study identified a strong association between a single-nucleotide polymorphism, rs738409 C>G (causing an isoleucine-to-methionine substitution at position $148, \mathrm{I} 148 \mathrm{M}$ ), in the patatin-like phospholipase domain containing protein 3 (PNPLA3) gene and hepatic fat content (9). In addition, a strong association between PNPLA3 genotype and elevated alanine aminotransferase levels as well as hepatic fat content was confirmed in other populations (10-16). Although this gene was discovered to be associated with steatosis in patients with nonalcoholic fatty liver disease (12), data are emerging on its association with other liver diseases, including hepatitis $\mathrm{C}$ virus cirrhosis (17) and alcoholic cirrhosis (18). We performed a systematic review and meta-analysis of studies to examine the association between the presence of the PNPLA3 rs738409 polymorphism and the spectrum of ALD.

\section{METHODS}

\section{Identification and retrieval of primary studies}

We performed search of PubMed/Medline, Embase, and Cochrane for full-length articles in English examining PNPLA3 polymorphism association among ALD patients. We followed the MOOSE (Meta-analysis of Observational Studies in Epidemiology) guidelines (19). The initial medical subject heading search terms were "liver cirrhosis, alcoholic," and "adiponutrin, human" and expanded search using "rs738409" and "patatin-like phospholipase domain-containing 3 protein, human.” All databases were searched from their inception through September 2014. Articles were selected for full text review based on title and abstract. Manual search of the bibliographies of retrieved publications was done by two independent investigators (H.S. and A.K.S.) to increase yield of potentially relevant articles.

\section{Inclusion and exclusion criteria}

Inclusion and exclusion criteria were defined at the time of study conception and before data collection. For inclusion into the meta-analysis, a study had to (i) include patients with alcohol dependence; (ii) assess the presence of the PNPLA3 variant (rs738409 C>G); (iii) define the ALD spectrum to AFL: steatosis on liver ultrasound in the absence of elevated liver enzymes, ALI: liver steatosis accompanied by elevated amino transferases in the absence of cirrhosis, AC: confirmed by biopsy or clinical evaluation supported by hematological, biochemical, and/or radiologic imaging findings, and HCC: diagnostic findings on triple phase magnetic resonance imaging or computed tomography or on histological examination of the liver tissue; and (iv) be published as a full-length article. We excluded studies (i) without gene frequency and/or odds ratio (OR) data and (ii) including subjects with other liver disease etiologies without separate data among ALD patients.

\section{Study selection and data extraction}

Two reviewers (H.S. and A.K.S.) independently examined the studies for the inclusion and exclusion criteria and also extracted the data from the studies included in the analysis. The reviewers resolved discrepancies by jointly reviewing the study in question. Studies included in the analysis were reviewed for (i) study characteristics: author and year of publication, and study design (population based or not, using controls or not); (ii) study population: ALD spectrum and the sample sizes; (iii) frequencies of PNPLA3 polymorphism genotypes (rs738409 $\mathrm{CC}, \mathrm{CG}$, and GG): among healthy controls and ALD patients; and (iv) ORs: for association of PNPLA3 polymorphism and spectrum of ALD and for severity of ALD among diseased drinkers. Corresponding authors of studies included in the analysis were contacted to obtain the individual participant data.

\section{End points and outcomes}

Our study end points were (i) alcohol-related fatty liver (FL), ALI, AC, or HCC among drinkers compared with healthy controls and (ii) severity of ALD among drinkers. Healthy controls were defined as subjects without evidence of AFL, ALI, AC, or HCC irrespective of their drinking status as our primary aim was to examine the association of PNPLA3 polymorphisms with the predisposition to ALD.

We also performed the subgroup analyses for patient demographics (age, gender, and ethnicity) using the individual participant data.

\section{Assessment of study quality}

The quality of included studies was assessed independently by two authors (H.S. and A.K.S.) using the Newcastle-Ottawa Quality Assessment Scale for case-control studies (20). This scale has two different instruments for assessing case-control and cohort studies. Each instrument includes measures of quality in three domains: selection, comparability, and exposure. A study can receive up to one point for each of four areas meas- 
ured within the selection domain and for each of three areas measured within the exposure domain. A maximum of two points can be assigned within the comparability domain. The highest possible score is nine. High-quality studies were considered to have a score of seven or greater. Any discrepancies between the two authors were addressed by a joint reevaluation of the original article.

We also assessed the Hardy-Weinberg equilibrium (HWE) to assess genotype frequencies in the included studies. As the deviation from HWE in controls has been associated with problems in the design and conduct of genetic association studies particularly because of population stratification, genotyping error, or selection bias $(21,22)$, the magnitude of deviations from HWE and its statistical significance are reported. HWE analysis was performed among the healthy controls using the $\chi^{2}$ test $\left(\chi^{2}\right.$ value $<3.84$ indicating allele frequency to be in HWE). If a study showed a significant deviation of HWE, we planned to perform sensitivity analyses excluding the studies which deviated from HWE (if any) as recommended (23).

\section{Statistical analysis}

The strength of the association between rs738409 and ALD prevalence was expressed by OR and their corresponding 95\% confidence interval. Random effects model was used for analyzing the pooled data for all the analyses (24). Heterogeneity was measured by the between-study variance using the $I^{2}$ statistics (25) with a cutoff of $\geq 50 \%$ and $\chi^{2}$ test with $P<0.10$ (25). When there was heterogeneity with only two studies in the analysis, we reviewed both the studies for any differences to explain the heterogeneity. For heterogeneous data on analysis with more than two studies, we took stepwise approach: (i) excluding study with different ethnicity on Mestizio subjects, (ii) excluding two studies with highest and lowest OR, and (iii) meta-regression if needed. To assess the extent of publication bias, both Egger's test and the Begg and Mazumdar's test were used on unadjusted analyses $(26,27)$. Funnel plots were assessed by two independent investigators (H.S. and A.K.S.). At least two studies in the analyses were needed to examine the heterogeneity and three studies for examining any publication bias.

To examine independent association of rs738409 and ALD spectrum, generalized linear mixed models were built for patient demographics using the individual participant data. This statistical method was chosen to take into account the differences between the studies and is equivalent to the random effects model used for our main analysis. Data were not controlled for body mass index, given that only two of the five studies had information on this variable. First unadjusted odds for a particular outcome were assessed comparing the various PNPLA3 polymorphisms. Then, in a stepwise manner age and gender were entered into the model to examine independent association of PNPLA3 polymorphisms as well as individual demographics on the outcome. All statistical analyses were performed using the Comprehensive Meta-analysis software (Biostat, Englewood, NJ).

\section{RESULTS}

\section{Baseline study characteristics}

A total of 254 citations were retrieved on initial search. After reviewing article titles and abstracts, a total of 14 studies were included for full-text review (Figure 1). Of these, four studies (28-31) were excluded because of unavailability of data for analysis and/or were not full manuscripts, leaving 10 studies involving 4,112 patients for this meta-analysis. All 10 studies reported PNPLA3 polymorphism data on AC, 4 studies each on ALI and HCC, whereas only one study reported data on AFL (Table 1). Of the 10 studies, 7 recruited healthy controls $(18,32-37)$, whereas the other 3 had no control group (38-40). Healthy controls were heavy drinkers without liver disease in two studies $(18,32)$, or nondrinkers without liver disease in four studies $(33,34,36,37)$. One study included both drinkers and nondrinkers without liver disease (35). The baseline characteristics of the included studies are reported in Table 1. All studies included subjects with Caucasian ethnicity except one study that included Mestizio subjects, people from Mexico with mixed European and Native American ancestry (32).

\section{Assessment of study quality}

Based on the Newcastle-Ottawa Scale, half of the included studies (five) were considered as high-quality studies (Supplementary Table S1 online). In addition, all seven studies reporting genotype frequencies for control population were in HWE (Supplementary Table S2).

\section{PNPLA3 polymorphism (rs738409) in ALD compared with healthy controls}

A total of 7 studies involving 2,878 ALD patients and 4,091 controls were analyzed. Compared with healthy controls, prevalence of the PNPLA3 polymorphism rs738409 was assessed in patients

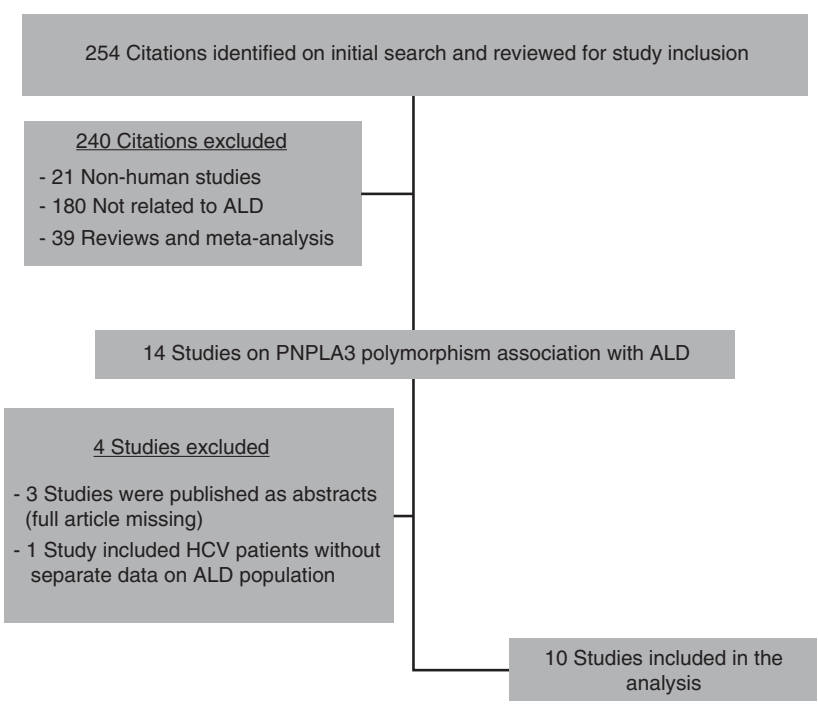

Figure 1. Attrition diagram for study inclusion. ALD, alcoholic liver disease; HCV, hepatitis C virus; PNPLA3, patatin-like phospholipase domain protein 3. 


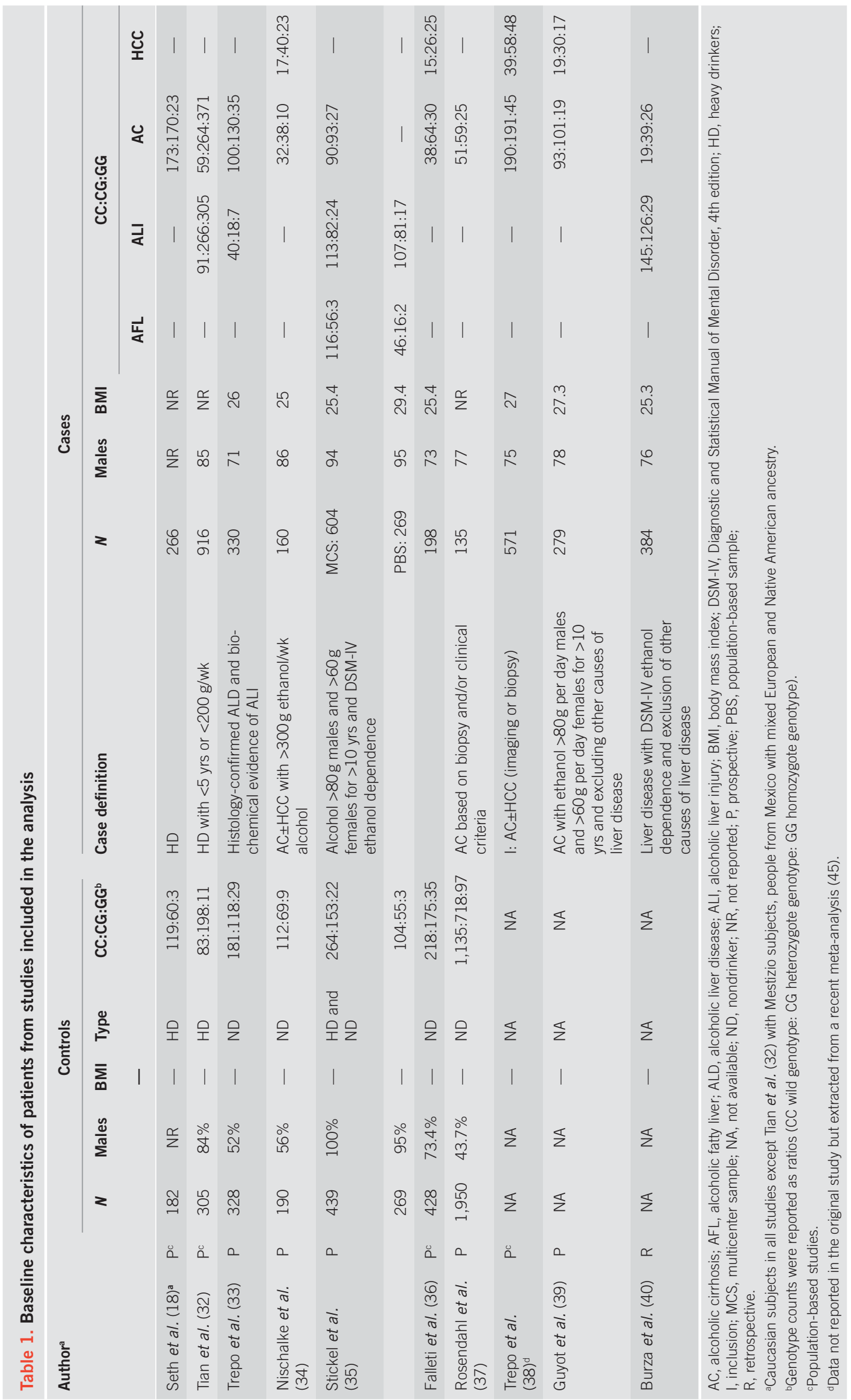


with AFL (1 study), ALI (3 studies), AC (7 studies), and HCC (2 studies).

Alcoholic fatty liver. The OR of the rs738409 CG and GG genotypes as compared with CC genotype in AFL was similar to controls when data were pooled from population-based and multicenter samples in one study (35): 0.74 (0.54-1.03) and 0.62 (0.13-2.93), respectively (Figures 2a and 3a). The data were homogeneous for both analyses with respective values of $I^{2}=0 \%$, $P=0.69$ and $I^{2}=45.98 \%, P=0.17$.

Alcoholic liver injury. The OR of rs738409 CG genotype compared with CC genotype was 1.45 (1.24-1.69) on comparing patients with ALI with healthy controls (Figure 2b). Data were homogeneous $\left(I^{2}=0 \%, P=0.995\right)$ without any publication bias as assessed by Egger's test $(P=0.569)$ or Begg and Mazumdar's test $(P=0.5)$. Similar OR for the rs738409 GG genotype was 2.22 (1.50-3.28) as compared with healthy controls (Figure 3b). Data were homogeneous $\left(I^{2}=0 \%, P=0.524\right)$ without publication bias as assessed by Egger's test $(P=0.182)$ or Begg and Mazumdar's test $(P=0.120)$.

Alcoholic cirrhosis. The OR of rs738409 CG genotype compared with CC genotype was 2.09 (1.79-2.44) on comparing patients with $\mathrm{AC}$ with healthy controls (Figure 2c). Data were homogeneous $\left(I^{2}=0 \%, P=0.989\right)$ without publication bias as assessed by Egger's test $(P=0.17)$ or Begg and Mazumdar's test $(P=1.0)$. Similar OR for the rs738409 GG genotype was 3.37 (2.49-4.575; Figure 3c). Data were homogeneous $\left(I^{2}=0 \%, P=0.42\right)$ without publication bias as assessed by Egger's test $(P=0.46)$ or Begg and Mazumdar's test $(P=0.31)$.

Hepatocellular carcinoma. The OR of rs738409 CG genotype compared with CC genotype was 2.87 (1.61-5.10) on comparing HCC patients with healthy controls (Figure 2d). Data were homogeneous $\left(I^{2}=35.43 \%, P=0.21\right)$. Similar OR for the rs $738409 \mathrm{GG}$

\begin{tabular}{|c|c|c|c|}
\hline \multirow[t]{2}{*}{$\begin{array}{l}\text { a } \\
\text { Study name }\end{array}$} & \multicolumn{3}{|c|}{$\underline{\text { Statistics for each study }}$} \\
\hline & $\begin{array}{l}\text { Odds } \\
\text { ratio }\end{array}$ & $\begin{array}{l}\text { Lower } \\
\text { limit }\end{array}$ & $\begin{array}{c}\text { Upper } \\
\text { limit }\end{array}$ \\
\hline Stickel, 2011 MCS & 0.770 & 0.532 & 1.114 \\
\hline \multirow[t]{2}{*}{ Stickel, 2011 PS } & 0.660 & 0.340 & 1.281 \\
\hline & 0.742 & 0.538 & 1.025 \\
\hline \multicolumn{4}{|l|}{ b } \\
\hline \multirow[t]{2}{*}{$\underline{\text { Study name }}$} & \multicolumn{3}{|c|}{$\underline{\text { Statistics for each study }}$} \\
\hline & $\begin{array}{l}\text { Odds } \\
\text { ratio }\end{array}$ & $\begin{array}{l}\text { Lower } \\
\text { limit }\end{array}$ & $\begin{array}{l}\text { Upper } \\
\text { limit }\end{array}$ \\
\hline Trepo, 2011 & 1.430 & 1.019 & 2.007 \\
\hline Stickel, 2011 MCS & 1.420 & 1.024 & 1.968 \\
\hline Stickel, 2011 PS & 1.530 & 0.949 & 2.467 \\
\hline \multirow[t]{2}{*}{ Tian, 2010} & 1.450 & 1.164 & 1.806 \\
\hline & 1.447 & 1.243 & 1.685 \\
\hline \multicolumn{4}{|l|}{ C } \\
\hline \multirow[t]{2}{*}{$\underline{\text { Study name }}$} & \multicolumn{3}{|c|}{$\underline{\text { Statistics for each study }}$} \\
\hline & $\begin{array}{l}\text { Odds } \\
\text { ratio }\end{array}$ & $\begin{array}{l}\text { Lower } \\
\text { limit }\end{array}$ & $\begin{array}{l}\text { Upper } \\
\text { limit }\end{array}$ \\
\hline Trepo, 2011 & 2.080 & 1.149 & 3.766 \\
\hline Stickel, 2011 MCS & 2.010 & 1.439 & 2.808 \\
\hline Seth, 2010 & 1.950 & 1.339 & 2.839 \\
\hline Tian, 2010 & 2.250 & 1.743 & 2.905 \\
\hline Nischalke, 2011 & 1.930 & 1.103 & 3.378 \\
\hline \multirow[t]{2}{*}{ Falleti, 2011} & 2.069 & 1.322 & 3.239 \\
\hline & 2.089 & 1.791 & 2.435 \\
\hline \multicolumn{4}{|l|}{ d } \\
\hline \multirow[t]{2}{*}{$\underline{\text { Study name }}$} & \multicolumn{3}{|c|}{$\underline{\text { Statistics for each study }}$} \\
\hline & $\begin{array}{l}\text { Odds } \\
\text { ratio }\end{array}$ & $\begin{array}{l}\text { Lower } \\
\text { limit }\end{array}$ & $\begin{array}{l}\text { Upper } \\
\text { limit }\end{array}$ \\
\hline Nischalke, 2011 & 3.820 & 2.010 & 7.260 \\
\hline Falleti, 2011 & 2.123 & 1.091 & 4.132 \\
\hline & 2.868 & 1.613 & 5.099 \\
\hline
\end{tabular}
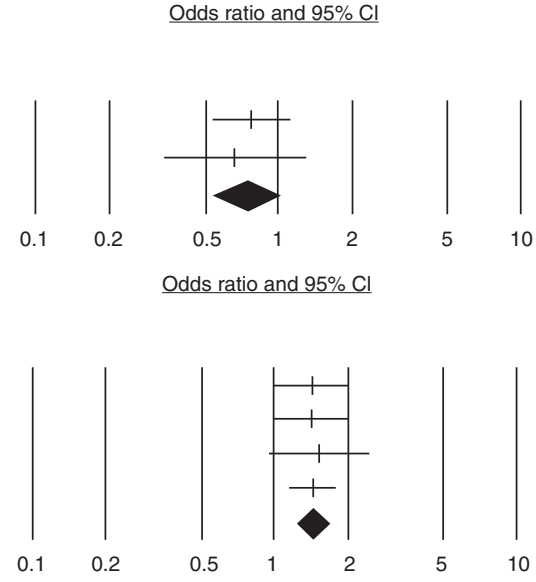

Odds ratio and $95 \% \mathrm{Cl}$
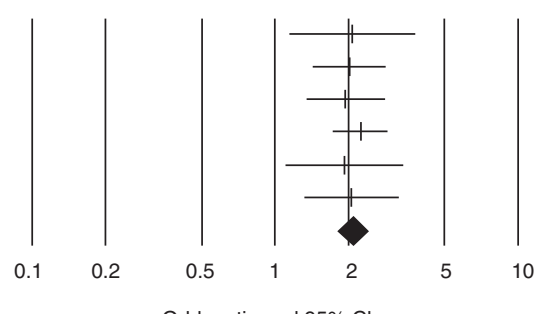

Odds ratio and $95 \% \mathrm{Cl}$

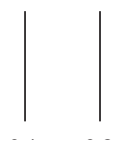

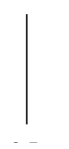

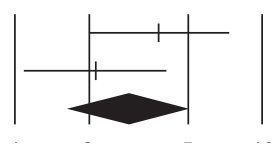

Figure 2. Forest plots showing the effect size with (95\% confidence interval $(\mathrm{CI})$ ) on the pooled data for the association between PNPLA3 (patatin-like phospholipase domain protein 3) polymorphism (CG vs. CC) and alcoholic liver disease (ALD). (a) Fatty liver, (b) alcoholic liver injury, (c) alcoholic cirrhosis, and (d) hepatocellular carcinoma vs. disease-free individuals. The bottom line in the statistics for each study heading is the pooled effect size analyzed using the random effects model. The odds ratio (OR) of $>1$ denotes risk for the respective outcome or positive association and OR $<1$ indicates protective effect or negative association. The $95 \% \mathrm{Cl}$ not crossing 1 indicates a significant association. MCS, multicenter sample; PS, population-based sample. 
genotype was $12.41(6.99-22.03)$ as compared with controls with homogeneous data $\left(I^{2}=0 \%, P=0.41\right.$; Figure $\left.3 d\right)$.

\section{PNPLA3 polymorphism (rs738409) and severity of alcoholic liver disease}

A total of 8 studies involving 3,711 ALD patients were pooled for these analyses (Figure 4a-e).

AC vs. AFL. The OR of CG and GG genotypes among AC patients compared with AFL was 2.62 (1.73-3.97) and 8.45 (2.52-28.37), respectively, in one study (35) (data not shown in the forest plots).

AC vs. ALI. The OR of rs738409 CG genotype compared with CC genotype was 1.98 (1.24-3.17; Figure 4a). There was significant heterogeneity among the studies $\left(I^{2}=67.04, P=0.048\right)$. No publication bias was detected by Egger's test $(P=0.11)$ or Begg and Mazumdar's test $(P=0.12)$. Sensitivity analysis after excluding the study with the Mestizio subjects (32) showed similar effect 2.59 (1.69-3.98) without any heterogeneity $\left(I^{2}=0, P=0.66\right)$.
The OR (95\% CI) of developing AC compared with ALI was 3.86 (1.18-12.60) in the presence of rs738409 GG compared with CC genotype (Figure $4 \mathbf{b})$. The data were heterogeneous $\left(I^{2}=76 \%\right.$, $P=0.039)$. Differences on proportion of patients with $\mathrm{AC}$ in the two studies included in this analysis, $\sim 80 \%$ in one study (33) and only $22 \%$ in the other study (40), probably explains this heterogeneity. Publication bias could not be done with only two studies in this analysis. In addition, OR of rs738409 GG genotype compared with CG genotype was $2.90(1.53-5.49)$ in one study (40).

HCC vs. AC. The OR of rs738409 CG compared with CC genotype was 1.43 (0.76-2.72) (Figure 4c). The data were homogeneous $\left(I^{2}=33, P=0.22\right)$. Similarly, OR of rs738409 GG genotype vs. CC genotype was 2.81 (1.57-5.01; Figure 4d). However, there was significant heterogeneity for this analysis $\left(I^{2}=70.38 \%, P=0.018\right)$. No publication bias was detected by Egger's test $(P=0.36)$ or Begg and Mazumdar's test $(P=0.0 .490)$. Sensitivity analysis performed after excluding the study with the lowest (39) and highest OR showed similar effect: 2.91 (1.44-5.86) with no

\begin{tabular}{|c|c|c|c|}
\hline \multirow[t]{2}{*}{$\begin{array}{l}\text { a } \\
\text { Study name }\end{array}$} & \multicolumn{3}{|c|}{ Statistics for each study } \\
\hline & $\begin{array}{l}\text { Odds } \\
\text { ratio }\end{array}$ & $\begin{array}{c}\text { Lower } \\
\text { limit }\end{array}$ & $\begin{array}{l}\text { Upper } \\
\text { limit }\end{array}$ \\
\hline Stickel, 2011 MCS & 0.330 & 0.094 & 1.159 \\
\hline \multirow[t]{2}{*}{ Stickel, 2011 PS } & 1.690 & 0.231 & 12.359 \\
\hline & 0.618 & 0.130 & 2.931 \\
\hline \multicolumn{4}{|l|}{ b } \\
\hline \multirow[t]{2}{*}{$\underline{\text { Study name }}$} & \multicolumn{3}{|c|}{ Statistics for each study } \\
\hline & $\begin{array}{l}\text { Odds } \\
\text { ratio }\end{array}$ & $\begin{array}{c}\text { Lower } \\
\text { limit }\end{array}$ & $\begin{array}{l}\text { Upper } \\
\text { limit }\end{array}$ \\
\hline Trepo, 2011 & 1.930 & 1.119 & 3.328 \\
\hline Stickel, 2011 MCS & 2.330 & 1.272 & 4.267 \\
\hline \multirow[t]{2}{*}{ Stickel, 2011 PS } & 4.750 & 1.080 & 20.896 \\
\hline & 2.222 & 1.504 & 3.284 \\
\hline c & \multicolumn{3}{|c|}{ Statistics for each study } \\
\hline Study name & $\begin{array}{l}\text { Odds } \\
\text { ratio }\end{array}$ & $\begin{array}{l}\text { Lower } \\
\text { limit }\end{array}$ & $\begin{array}{l}\text { Upper } \\
\text { limit }\end{array}$ \\
\hline Stickel, 2011 MCS & 2.790 & 1.547 & 5.031 \\
\hline Seth, 2010 & 7.340 & 2.194 & 24.550 \\
\hline Nischalke, 2011 & 3.890 & 1.458 & 10.377 \\
\hline Falleti, 2011 & 4.850 & 2.669 & 8.813 \\
\hline \multirow[t]{2}{*}{ Rosendhal, 2014} & 2.700 & 1.885 & 3.868 \\
\hline & 3.372 & 2.485 & 4.575 \\
\hline \multirow[t]{2}{*}{ Study name } & \multicolumn{3}{|c|}{ Statistics for each study } \\
\hline & $\begin{array}{l}\text { Odds } \\
\text { ratio }\end{array}$ & $\begin{array}{c}\text { Lower } \\
\text { limit }\end{array}$ & $\begin{array}{c}\text { Upper } \\
\text { limit }\end{array}$ \\
\hline Nischalke, 2011 & 16.840 & 6.682 & 42.441 \\
\hline Falleti, 2011 & 10.238 & 4.919 & 21.309 \\
\hline & 12.407 & 6.986 & 22.034 \\
\hline
\end{tabular}
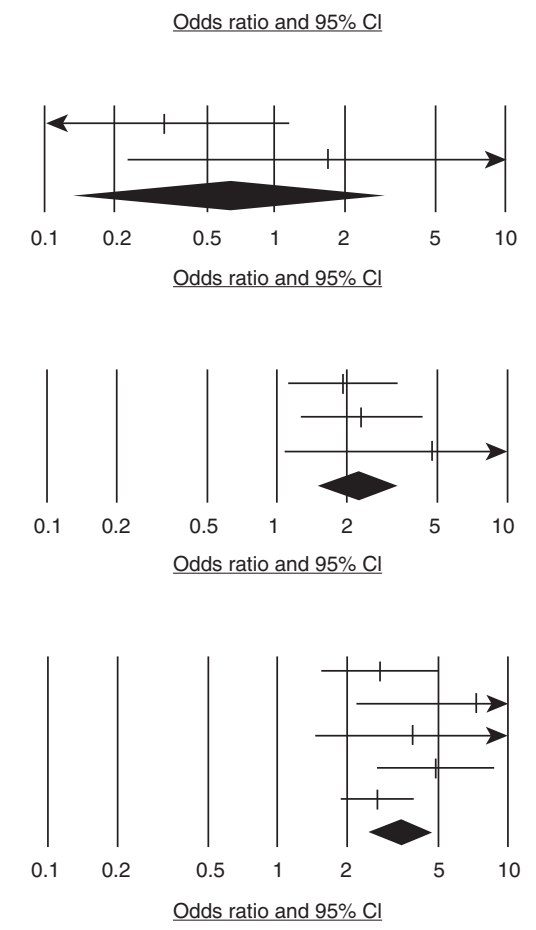

Figure 3. Forest plots showing the effect size with odds ratio (95\% confidence interval $(\mathrm{CI})$ ) on the pooled data for the association between PNPLA3 (patatin-like phospholipase domain protein 3) polymorphism (GG vs. CC) and alcoholic liver disease (ALD). (a) Fatty liver, (b) alcoholic liver injury, (c) alcoholic cirrhosis, and (d) hepatocellular carcinoma vs. disease-free individuals. The bottom line in the statistics for each study heading is the pooled effect size analyzed using the random effects model. The odds ratio (OR) of $>1$ denotes risk for the respective outcome or positive association and $\mathrm{OR}<1$ indicates protective effect or negative association. The $95 \% \mathrm{Cl}$ not crossing 1 indicates a significant association. MCS, multicenter sample; PS, population-based sample. 
heterogeneity ( $\left.I^{2}=20.37 \%, P=0.26\right)$. OR of rs738409 GG vs. CG genotype was $2.10(1.22-3.63)$ with homogeneous data $\left(I^{2}=0 \%\right.$, $P=0.912$; Figure 4e).

\section{Subgroup analyses}

Ethnicity analysis. After excluding the study recruiting Mestizo population (32), pooled effect size remained in the same direction on the outcomes including this study (Figures $\mathbf{2} \mathbf{b}, \mathbf{c}$ and $\mathbf{4 a}$ ) - CG genotype compared with CC genotype for ALI vs. healthy controls: 1.45 (1.17-1.78); CG genotype compared with CC genotype for AC vs. healthy controls: 1.99 (1.61-2.46); and CG genotype compared with CC genotype for AC vs. ALI: 2.59 (1.69-3.98).

Analysis of good-quality studies: on analyzing five good-quality studies, data remain unchanged as reported in Supplementary Table S2.

Individual participant data analyses. Individual participant data were obtained on 2,033 ALD patients (734 ALI; 1,153 AC without HCC; and 146 AC with HCC) from 5 studies (Table 2). Data on 487 healthy controls (drinkers with normal blood tests) a Study name

Trepo, 2011

Tian, 2010

Burza, 2013

b

Study name

Trepo, 2011

Burza, 2013

c

Study name

Nischalke, 2011

Falleti, 2011

d

Study name

Trepo, 2012

Nischalke, 2011

Guyot, 2013

Falleti, 2011

e

Study name

Nischalke, 2011

Falleti, 2011

\begin{tabular}{lcc}
\multicolumn{3}{c}{ Statistics for each study } \\
$\begin{array}{c}\text { Odds } \\
\text { ratio }\end{array}$ & $\begin{array}{c}\text { Lower } \\
\text { limit }\end{array}$ & $\begin{array}{c}\text { Upper } \\
\text { limit }\end{array}$ \\
.860 & 1.548 & 5.284 \\
.430 & 1.149 & 1.779 \\
.360 & 1.298 & 4.292 \\
.982 & 1.238 & 3.172
\end{tabular}

Statistics for each study

$\begin{array}{ccc}\begin{array}{c}\text { Odds } \\ \text { ratio }\end{array} & \begin{array}{c}\text { Lower } \\ \text { limit }\end{array} & \begin{array}{c}\text { Upper } \\ \text { limit }\end{array} \\ 2.040 & 0.832 & 5.002 \\ 6.840 & 3.351 & 13.963 \\ 3.856 & 1.180 & 12.599\end{array}$

Statistics for each study

$\begin{array}{ccc}\begin{array}{c}\text { Odds } \\ \text { ratio }\end{array} & \begin{array}{c}\text { Lower } \\ \text { limit }\end{array} & \begin{array}{c}\text { Upper } \\ \text { limit }\end{array} \\ 1.980 & 0.947 & 4.138 \\ 1.030 & 0.488 & 2.173 \\ 1.432 & 0.755 & 2.717\end{array}$

Statistics for each study

$\begin{array}{ccc}\begin{array}{c}\text { Odds } \\ \text { ratio }\end{array} & \begin{array}{c}\text { Lower } \\ \text { limit }\end{array} & \begin{array}{c}\text { Upper } \\ \text { limit }\end{array} \\ 4.700 & 2.627 & 8.410 \\ 4.330 & 1.680 & 11.160 \\ 1.720 & 1.209 & 2.447 \\ 2.110 & 0.922 & 4.826 \\ 2.806 & 1.571 & 5.013\end{array}$

Statistics for each study

$\begin{array}{ccc}\begin{array}{c}\text { Odds } \\ \text { ratio }\end{array} & \begin{array}{c}\text { Lower } \\ \text { limit }\end{array} & \begin{array}{c}\text { Upper } \\ \text { limit }\end{array} \\ 2.190 & 0.922 & 5.202 \\ 2.050 & 1.019 & 4.125 \\ 2.104 & 1.222 & 3.625\end{array}$

Odds ratio and $95 \% \mathrm{Cl}$

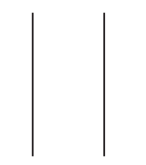

$\begin{array}{ll}0.1 & 0.2\end{array}$

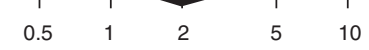

Odds ratio and $95 \% \mathrm{Cl}$

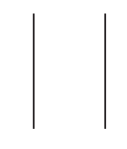

$\begin{array}{ll}0.1 & 0.2\end{array}$

Odds ratio and $95 \% \mathrm{Cl}$

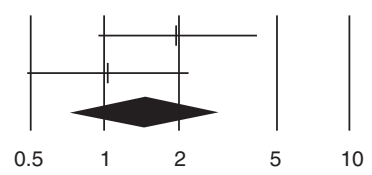

Odds ratio and $95 \% \mathrm{Cl}$
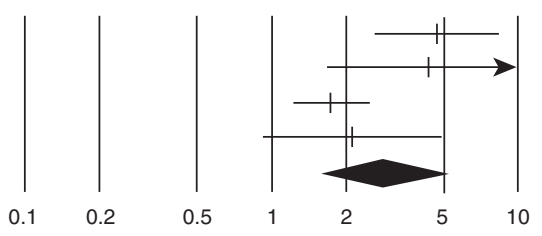

Odds ratio and $95 \% \mathrm{Cl}$

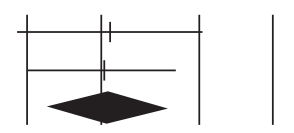

Figure 4. Forest plots showing the effect size with odds ratio (95\% confidence interval (CI)) on the pooled data for the association of PNPLA3 (patatin-like phospholipase domain protein 3) polymorphism among alcoholic liver disease (ALD) spectrum patients. (a) Alcoholic cirrhosis compared with alcoholic liver injury (CG vs. CC), (b) alcoholic cirrhosis compared with alcoholic liver injury (GG vs. CC), (c) hepatocellular carcinoma compared with alcoholic cirrhosis (CG vs. CC), (d) hepatocellular carcinoma compared with alcoholic cirrhosis (GG vs. CC), and (e) hepatocellular carcinoma compared with alcoholic cirrhosis (GG vs. CG). The bottom line in the statistics for each study heading is the pooled effect size analyzed using the random effects model. The odds ratio (OR) of $>1$ denotes risk for the respective outcome or positive association and $\mathrm{OR}<1$ indicates protective effect or negative association. The 95\% $\mathrm{Cl}$ not crossing 1 indicates a significant association. 


\begin{tabular}{|c|c|c|c|c|c|}
\hline Study & $N$ & Age & $N(\%) \mathrm{M}$ & BMI & CC:CG:GG \\
\hline Burza et al. (40) & 84 ALD with AC & $54.2 \pm 11^{*}$ & $63(75)$ & $26.7 \pm 4.7$ & 19:39:26 \\
\hline Nischalke et al. (34) & $80 \mathrm{AC}$ without $\mathrm{HCC}$ & $57 \pm 10.2$ & $69(86)$ & $26.7 \pm 6.8^{*}$ & $32: 38: 10$ \\
\hline \multirow[t]{2}{*}{ Falleti et al. (36) } & $132 \mathrm{AC}$ without HCC & $54 \pm 9.4$ & $82(62)$ & $24.4 \pm 4.1$ & $38: 64: 30$ \\
\hline & $66 \mathrm{AC}$ with $\mathrm{HCC}$ & $60.6 \pm 8.4^{*}$ & $62(94)^{*}$ & $27.3 \pm 3.9^{*}$ & $15: 26: 25$ \\
\hline Seth et al. (cases) (18) & 375 ALD with AC & $49 \pm 9.7^{*}$ & $271(72)$ & NA & 173:170:32 \\
\hline Seth et al. (controlsa) (18) & 182 & $43.4 \pm 9.8$ & $133(73)$ & NA & 119:60:3 \\
\hline
\end{tabular}

were obtained from two studies (Table 2). Pooled data comparing the OR (for AC vs. healthy controls) of CG vs. CC, GG vs. CC, and GG vs. CG were 1.84 (1.47-2.31), 4.40 (2.98-6.50), and 2.40 (1.62-3.55), respectively. Similar OR for HCC vs. healthy controls was 2.96 (1.88-4.66), 13.30 (7.61-23.27), and 4.50 (2.71-7.46), respectively.

Generalized linear mixed model analysis on the individual participant data showed unadjusted OR for AC vs. ALI comparing CG with CC, GG with CC, and GG with CG to be 1.9 (1.3-2.9), 3.0 (2.0-4.6), and $1.6(1.1-2.3)$, respectively. After adding age and gender into the model in a stepwise manner, the significance of the OR remained unchanged and in the same direction (Table 3). Participant age but not the gender independently predicted development of cirrhosis (Table 3). Similar unadjusted OR on the development of HCC among AC patients was 1.5 (0.5-2.6), 2.9 (0.8-11.1), and 2.1 (0.1-68.1), respectively. The data for HCC remained significant with wide confidence interval probably because of small sample size, with data on HCC available on only 358 patients from two studies.

\section{DISCUSSION}

The current meta-analysis demonstrates several important findings on the association of the PNPLA3 gene polymorphisms with ALD. Compared with controls, prevalence of PNPLA3 polymorphisms was higher among patients with ALI, AC, and HCC in AC. Furthermore, the prevalence of these polymorphisms was higher among patients with AC compared with those with ALI or AFL and among AC patients with HCC compared with those without HCC. Data on prevalence of PNPLA3 polymorphisms were similar when drinkers with FL were compared with controls. Individual participant data also confirmed these observations.
The disease spectrum in both alcoholic and nonalcoholic fatty liver disease is similar and starts with fatty liver change followed by inflammation, fibrosis, and finally cirrhosis. Hepatic steatosis is seen in $90 \%$ of heavy alcohol drinkers and is usually macrovesicular (41-43). Fatty infiltration develops rapidly within 2 weeks and resolves with abstinence $(44,45)$. The similar polymorphism prevalence in drinkers with AFL and controls, as found in the current meta-analysis, blends well with the fact that AFL is a universal phenomenon in alcoholics and is reversible on abstinence. However, this is not true for ALI, AC, and HCC.

Stickel et al. (7) have reviewed previous studies on alcoholic dehydrogenase gene polymorphism in alcoholic patients and showed that results were inconsistent. The available data do not provide clear evidence that demonstrates a contribution of alcohol metabolism (alcohol dehydrogenase), antioxidant enzymes (CYP2E1, GSTM1, MnSOD), or cytokines (interleukin and tumor necrosis factors) genotype polymorphisms to the development of ALD (7). PNPLA3 is the first genetic marker that was confirmed by repeated studies to predispose to ALD and is associated with worse severity as we showed in the current meta-analysis.

Two recent meta-analyses have shown association of PNPLA3 with advanced fibrosis $(46,47)$. Heterogeneous data due to inclusion of patients with various liver disease etiologies was a limitation in one study (46). Furthermore, this study included only three studies on alcoholic liver disease $(29,33,35)$ in comparison with five studies in our current analysis (18,32-35). Our meta-analysis provides pooled data comparing ALD patients with healthy controls on the association of PNPLA3 polymorphisms with HCC in two studies $(34,36)$ and AC in four studies $(34,36,38,39)$. Furthermore, we also examine the association of the remaining spectrum of ALD and PNPLA3 polymorphisms including FL and ALI. Our study findings on the risk of fibrosis and AC are similar to the 


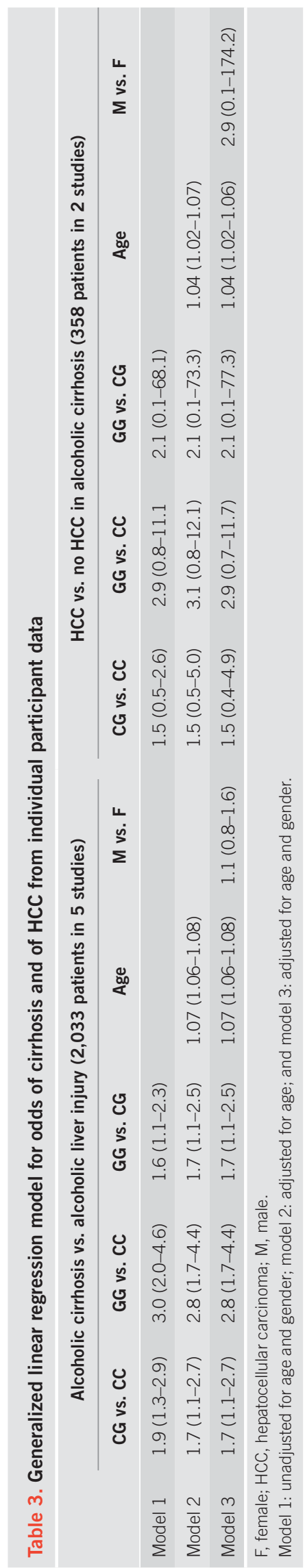

second meta-analysis except for lower OR for the GG genotype. This may be as this analysis included three citations published as abstracts (29-31) that were not included in our current analysis. In another meta-analysis, PNPLA3 polymorphisms among cirrhotics have been associated with HCC (48). Our meta-analysis in addition to confirming the findings from this study also examines the HCC risk in alcoholics compared with healthy controls. Furthermore, we also examined the association of PNPLA3 polymorphisms with the other spectrum of ALD.

Our analysis may be limited by the possibility of publication bias. In order to minimize this possibility and subsequently overestimation of the true effect size because of negative study identification failure (49), we combined searches from PubMed/Medline, Embase, and Cochrane with manual searches. Although we used procedures in agreement with current guidelines, we cannot formally rule out the possibility that we missed studies that were not accessible (49). Another limitation of this meta-analysis is the inclusion of case-control studies in which the potential for biases (e.g., selection and reporting) is higher when compared with randomized trials and they are more inherent to confounding factors. In the current analysis, the rs738409 genotype frequencies in the control group that followed the HWE is a strength of this study as sampling bias or coincidental gene association because of population stratification could be excluded (39), but some authors have shown that HWE testing is not a reliable way of detecting genotyping error and can certainly not exclude population stratification $(21,50)$. Finally, we were not able to retrieve all the individual participant data (only $46 \%$ of all individual participant data were obtained) from the included studies, especially the largest one by Stickel et al. (35) (1,419 patients). Therefore, we used the individual participant data for only the subgroup analyses and not our main outcome analyses.

In conclusion, the PNPLA3 rs738409 polymorphism is associated with increased risk for the entire spectrum of ALD among drinkers, and increased propensity for AC and HCC in ALI patients. Studies are needed to clarify the association of PNPLA3 and steatosis in alcohol drinkers. The PNPLA3 gene may potentially be a therapeutic target in ALD and in the selection of donor organs for transplantation of patients with ALD.

\section{ACKNOWLEDGMENTS}

We sincerely appreciate the help from David Hinds and co-authors (32) in providing the individual participant data on subjects included in their study.

\section{CONFLICT OF INTEREST}

Guarantor of the article: Ashwani K. Singal, MD, MS.

Specific author contributions: H.S.: study design, data collection, data analysis and interpretation, and writing the paper; E.R: data collection and writing the paper; A.E.: performing the HWE analysis and reviewing the manuscript; D.S., H.D.N, E.F., M.A.B., J.L., S.R., A.M., S.G.C., P.T., S.U., A.D., and C.P.D.: provided individual participant data and reviewed the paper; A.K.S.: study design, data collection, data analysis and interpretation, reviewing the paper, and study supervision.

Financial support: None.

Potential competing interests: None. 


\section{Study Highlights}

\section{WHAT IS CURRENT KNOWLEDGE}

The patatin-like phospholipase domain protein 3 (PNPLA3) gene polymorphism confers risk of steatosis.

This is also associated with cirrhosis and hepatocellular carcinoma (HCC) in alcoholic liver disease (ALD).

\section{WHAT IS NEW HERE}

PNPLA3 polymorphism increases risk for entire spectrum of ALD.

The magnitude of this association increases in parallel to increasing severity of liver disease from alcoholic liver injury to alcoholic cirrhosis to hepatocellular carcinoma.

Data on association of PNPLA3 polymorphisms with alcoholic fatty liver are inconsistent.

Data remained unchanged for separate analyses (i) on individual patient data from five studies and (ii) on five good-quality studies.

\section{REFERENCES}

1. Lelbach WK. Cirrhosis in the alcoholic and its relation to the volume of alcohol abuse. Ann NY Acad Sci 1975;252:85-105.

2. Gao B, Bataller R. Alcoholic liver disease: pathogenesis and new therapeutic targets. Gastroenterology 2011;141:1572-85.

3. Reed T, Page WF, Viken RJ et al. Genetic predisposition to organ-specific endpoints of alcoholism. Alcohol Clin Exp Res 1996;20:1528-33.

4. Flores $\mathrm{YN}$, Yee HF, Leng $\mathrm{M}$ et al. Risk factors for chronic liver disease in Blacks, Mexican Americans, and Whites in the United States: results from NHANES IV, 1999-2004. Am J Gastroenterol 2008;103:2231-8.

5. Mann RE, Smart RG, Govoni R. The epidemiology of alcoholic liver disease. Alcohol Res Health 2003;27:209-19.

6. Said A, Williams J, Holden J et al. The prevalence of alcohol-induced liver disease and hepatitis $C$ and their interaction in a tertiary care setting. Clin Gastroenterol Hepatol 2004;2:928-34.

7. Stickel F, Osterreicher $\mathrm{CH}$. The role of genetic polymorphisms in alcoholic liver disease. Alcohol Alcohol 2006;41:209-24.

8. Zintzaras E, Stefanidis I, Santos $\mathrm{M}$ et al. Do alcohol-metabolizing enzyme gene polymorphisms increase the risk of alcoholism and alcoholic liver disease? Hepatology 2006;43:352-61.

9. Romeo S, Kozlitina J, Xing C et al. Genetic variation in PNPLA3 confers susceptibility to nonalcoholic fatty liver disease. Nat Genet 2008;40: 1461-5.

10. Yuan X, Waterworth D, Perry JR et al. Population-based genome-wide association studies reveal six loci influencing plasma levels of liver enzymes. Am J Hum Genet 2008;83:520-8.

11. Kollerits B, Coassin S, Kiechl S et al. A common variant in the adiponutrin gene influences liver enzyme values. J Med Genet 2010;47:116-9.

12. Kotronen A, Johansson LE, Johansson LM et al. A common variant in PNPLA3, which encodes adiponutrin, is associated with liver fat content in humans. Diabetologia 2009;52:1056-60.

13. Kotronen A, Peltonen M, Hakkarainen A et al. Prediction of non-alcoholic fatty liver disease and liver fat using metabolic and genetic factors. Gastroenterology 2009;137:865-72.

14. Sookoian S, Castaño GO, Burgueño AL et al. A nonsynonymous gene variant in the adiponutrin gene is associated with nonalcoholic fatty liver disease severity. J Lipid Res 2009;50:2111-6.

15. Romeo S, Sentinelli F, Dash S et al. Morbid obesity exposes the association between PNPLA3 I148M (rs738409) and indices of hepatic injury in individuals of European descent. Int J Obes (Lond) 2010;34:190-4.

16. Kantartzis K, Peter A, Machicao F et al. Dissociation between fatty liver and insulin resistance in humans carrying a variant of the patatin-like phospholipase 3 gene. Diabetes 2009;58:2616-23.

17. Sato M, Kato N, Tateishi R et al. Impact of PNPLA3 polymorphisms on the development of hepatocellular carcinoma in patients with chronic hepatitis C virus infection. Hepatol Res 2014;44:E137-44.
18. Seth D, Daly AK, Haber PS et al. Patatin-like phospholipase domain containing 3: a case in point linking genetic susceptibility for alcoholic and nonalcoholic liver disease. Hepatology 2010;51:1463-5.

19. Stroup DF, Berlin JA, Morton SC et al. Meta-analysis of observational studies in epidemiology: a proposal for reporting. Meta-analysis Of Observational Studies in Epidemiology (MOOSE) group. JAMA 2000;283: 2008-12.

20. Wells GA, Shea B, O'Connell D et al. The Newcastle-Ottawa Scale (NOS) for assessing the quality of nonrandomised studies in meta-analyses [webpage on the Internet] Ottawa, ON: Ottawa Hospital Research Institute; 2011 [Accessed 10, 2014]. Available from: http://www.ohri.ca/programs/ clinical_epidemiology/oxford.asp.

21. Minelli C, Thompson JR, Abrams KR et al. How should we use information about HWE in the meta-analyses of genetic association studies? Int J Epidemiol 2008;37:136-46.

22. Rodriguez S, Gaunt TR, Day IN. Hardy-Weinberg equilibrium testing of biological ascertainment for Mendelian randomization studies. Am J Epidemiol 2009;169:505-14.

23. Thakkinstian A, McElduff P, D'Este C et al. A method for meta-analysis of molecular association studies. Stat Med 2005;24:1291-306.

24. DerSimonian R, Laird N. Meta-analysis in clinical trials. Control Clin Trials 1986;7:177-88.

25. Higgins JP, Thompson SG, Deeks JJ et al. Measuring inconsistency in metaanalyses. BMJ 2003;327:557-60.

26. Deeks JJ, Altman DG, Bradburn MJ. Statistical methods for examining heterogeneity and combining results from several studies in meta-analysis. In: Egger M, Smith GD, Altman DG (eds) Systematic Reviews in Health Care: Meta-Analysis in Context, 2nd (edn) BMJ Books: London, 2005, pp 285-312

27. Begg CB, Mazumdar M. Operating characteristics of a rank correlation test for publication bias. Biometrics 1994;50:1088-101.

28. Hamza S, Petit JM, Masson D et al. PNPLA3 rs738409 GG homozygote status is associated with increased risk of hepatocellular carcinoma in cirrhotic patients. J Hepatol 2012;56(Suppl 2):S281-82.

29. Way M, McQuillin A, Gurling HMD et al. The PNPLA3 I148M mutation significantly increases the risk of developing alcohol-related cirrhosis in alcohol-dependent individuals. J Hepatol 2013;58:S563-64.

30. Dutta AK. Genetic factors affecting susceptibility to alcoholic liver disease in an Indian population. Ann Hepatol 2013;12:901-7.

31. Nguyen-Khac E, Houchi H, Dreher M-L et al. Is PNPLA3 polymorphism involved in severe acute alcoholic hepatitis. Hepatology 2011;54:976A.

32. Tian C, Stokowski RP, Kershenobich D et al. Variant in PNPLA3 is associated with alcoholic liver disease. Nat Genet 2010;42:21-3.

33. Trépo E, Gustot T, Degré D et al. Common polymorphism in the PNPLA3/ adiponutrin gene confers higher risk of cirrhosis and liver damage in alcoholic liver disease. J Hepatol 2011;55:906-12.

34. Nischalke HD, Berger C, Luda C et al. The PNPLA3 rs738409 148M/M genotype is a risk factor for liver cancer in alcoholic cirrhosis but shows no or weak association in hepatitis C cirrhosis. PLoS One 2011;6:e27087.

35. Stickel F, Buch S, Lau K et al. Genetic variation in the PNPLA3 gene is associated with alcoholic liver injury in caucasians. Hepatology 2011;53: 86-95.

36. Falleti E, Fabris C, Cmet $\mathrm{S}$ et al. PNPLA3 rs738409C/G polymorphism in cirrhosis: relationship with the aetiology of liver disease and hepatocellular carcinoma occurrence. Liver Int 2011;31:1137-43.

37. Rosendahl J, Tönjes A, Schleinitz D et al. A common variant of PNPLA3 (p.I148M) is not associated with alcoholic chronic pancreatitis. PLoS One 2012;7:e29433.

38. Trepo E, Guyot E, Ganne-Carrie N et al. PNPLA3 (rs738409 C>G) is a common risk variant associated with hepatocellular carcinoma in alcoholic cirrhosis. Hepatology 2012;55:1307-8.

39. Guyot E, Sutton A, Rufat P et al. PNPLA3 rs738409, hepatocellular carcinoma occurrence and risk model prediction in patients with cirrhosis. J Hepatol 2013;58:312-8.

40. Burza MA, Molinaro A, Attilia ML et al. PNPLA3 I148M (rs738409) genetic variant and age at onset of at-risk alcohol consumption are independent risk factors for alcoholic cirrhosis. Liver Int 2014;34:514-20.

41. Edmondson HA, Peters RL, Frankel HH et al. The early stage of liver injury in the alcoholic. Medicine (Baltimore) 1967;46:119-29.

42. Naveau S, Giraud V, Borotto E et al. Excess weight risk factor for alcoholic liver disease. Hepatology 1997;25:108-11.

43. Crabb DW. Pathogenesis of alcoholic liver disease: newer mechanisms of injury. Keio J Med 1999;48:184-8. 
44. Lane BP, Lieber CS. Ultrastructural alterations in human hepatocytes following ingestion of ethanol with adequate diets. Am J Pathol 1966;49:593-603.

45. Tang-Barton P, Vas W, Weissman J et al. Focal fatty liver lesions in alcoholic liver disease: a broadened spectrum of CT appearances. Gastrointest Radiol 1985;10:133-7.

46. Singal AG, Manjunath H, Yopp AC et al. The effect of PNPLA3 on fibrosis progression and development of hepatocellular carcinoma: a meta-analysis. Am J Gastroenterol 2014;109:325-34.

47. Chamorro AJ, Torres JL, Miron-Canelo JA et al. Systematic review with meta-analysis: the I148M variant of patatin-like phospholipase domain- containing 3 gene (PNPLA3) is significantly associated with alcoholic liver cirrhosis. Aliment Pharmacol Ther 2014;40:571-81.

48. Trépo E, Nahon P, Bontempi G et al. Association between the PNPLA3 (rs738409 C > G) variant and hepatocellular carcinoma: evidence from a meta-analysis of individual participant data. Hepatology 2014;59:2170-7.

49. Thornton A, Lee P. Publication bias in meta-analysis: its causes and consequences. J Clin Epidemiol 2000;53:207-16.

50. Zou GY, Donner A. The merits of testing Hardy-Weinberg equilibrium in the analysis of unmatched case-control data: a cautionary note. Ann Hum Genet 2006;70:923-33. 